\title{
Prediction of thermodynamic state of the Gregoriev ice cap, Tien Shan, central Asia, in the future
}

\author{
Oleg NAGORNOV, ${ }^{1}$ Yuri KONOVALOV ${ }^{1}$ Vladimir MIKHALENKO ${ }^{2}$ \\ ${ }^{1}$ Moscow Engineering Physics Institute (Technical University), Kashirskoe shosse 31, 115409 Moscow, Russia \\ E-mail: nagornov@yandex.ru \\ ${ }^{2}$ Institute of Geography, Russian Academy of Sciences, 29 Staromonetny Street, 109017 Moscow, Russia
}

\begin{abstract}
We use a two-dimensional flowline model to study the flow of the Gregoriev ice cap, Tien Shan, central Asia. The model takes into account the transverse change of glacier width, data on the measured thickness of the glacier, the surface velocity at the glacier front, and mass-balance measurements in 1987 and 1988. The calculated ice velocity varies from 0 to $3 \mathrm{~m} \mathrm{a}^{-1}$ along the glacier flowline. The velocity maximum is shifted from the lowest part towards the middle part of the ice cap for the time interval considered (1980-2050) in the study. The derived changes of the glacier show the degradation and decrease of glacier extent on the south slope of Terskey Ala Tau, Tien Shan. Seasonal variations of temperature in the subsurface layer result in oscillations of stresses and velocities that are due to seasonal changes of viscosity. The consequent stresses can exceed the compressive/tensile strength that would produce crevasses.
\end{abstract}

\section{INTRODUCTION}

Flat-top glaciers are widespread in central Asia. They contain important paleoclimatic information that can be extracted from ice cores. Therefore, features of flow of such glaciers have to be studied for proper interpretation of the information preserved therein. Moreover, these glaciers are important sources of fresh water in the central Asian region, so prediction of the evolution of such glaciers is of special interest.

The Gregoriev ice cap is representative of flat-top glaciers located on the south slope of Terskey Ala Tau, Tien Shan (Fig. 1). Its average ice thickness is $100-110 \mathrm{~m}$, while its maximum length and width are 3.7 and $3 \mathrm{~km}$, respectively. It is a cold glacier without bottom sliding. Taking into account the measured data and using a flow model, which takes into account the transverse change of glacier width, we derive an evolution of the glacier shape, velocities and stresses in the ice, and predict the thermodynamic state from 2000 for the next 50 years.

The ice in a flat-top glacier flows mainly in the direction of principal slope, and ends at a steep glacier front. The transverse cross-section increases along slope and corresponds to a path through points P1-P13. For example, the width of the Gregoriev ice cap increases from 1.4 to $3 \mathrm{~km}$ (Fig. 1). Due to the complex geometry of the glacier, analytical models of ice flow are not valid (Hutter, 1983; Huybrechts and Oerlemans, 1988). To describe the ice flow we used a two-dimensional plane model that takes into account the transverse expansion in glacier width (Pattyn, 2000). By applying this model we determine the evolution of the thermodynamic state of the Gregoriev ice cap for 50 years and seasonal changes in the subsurface layers.

\section{MATHEMATICAL STATEMENT}

The glacier flow can be described by the mass-balance and equilibrium equations (Pattyn, 2000):

$$
\frac{\partial u}{\partial x}+\frac{u}{b} \frac{\mathrm{d} b}{\mathrm{~d} x}+\frac{\partial w}{\partial z}=0
$$

$$
\begin{aligned}
& \frac{\partial \sigma_{x x}}{\partial x}+\frac{\partial \sigma_{x z}}{\partial z}=0 \\
& \frac{\partial \sigma_{x z}}{\partial x}+\frac{\partial \sigma_{z z}}{\partial z}=\rho g
\end{aligned}
$$

where $x$ and $z$ are horizontal and vertical coordinates in the plane of the ice divide, $0<x<L_{0}, \quad h_{\mathrm{b}}(x)<z<h_{\mathrm{s}}(x)$, $u$ and $w$ are horizontal and vertical velocity components, respectively, $\sigma_{i k}$ is the stress tensor, $\rho$ is the density of ice, $g$ is the acceleration due to gravity, $h_{\mathrm{s}}(x)$ and $h_{\mathrm{b}}(x)$ are the upper and bottom surfaces of the glacier, and $b$ is the glacier width.

Integration over $z$ and differentiation by $x$ of Equation (1b) and the equation $\sigma_{x x}-\sigma_{z z}=2 \sigma_{x x}^{\prime}+\sigma_{y y}^{\prime}$ allows us to obtain

$$
\begin{aligned}
& 2 \frac{\partial \sigma_{x x}^{\prime}}{\partial x}+\frac{\partial \sigma_{y y}^{\prime}}{\partial x}+\frac{\partial^{2}}{\partial x^{2}} \int_{z}^{h_{\mathrm{s}}} \sigma_{x z}^{\prime} \mathrm{d} z+\frac{\partial \sigma_{x z}^{\prime}}{\partial z}+\frac{\mathrm{d}}{\mathrm{d} x}\left(\left.\sigma_{z z}\right|_{z=h_{\mathrm{s}}}\right) \\
& \quad=\rho g \frac{\mathrm{d} h_{\mathrm{s}}}{\mathrm{d} x}
\end{aligned}
$$

where $\sigma_{i k}^{\prime}$ is the stress deviator; $(i, k \equiv x, y, z)$. This equation differs from the similar equation of Pattyn (2000) by the last term on the left side of Equation (2). This term is important for steep slopes.

The stress deviator is connected with the strain-rate tensor by Glen's law (Paterson, 1994):

$$
\sigma_{i k}^{\prime}=2 \eta \dot{\varepsilon}_{i k}
$$

where $\eta$ is viscosity (Paterson, 1994):

$$
\eta=\frac{1}{2} A(T)^{-\frac{1}{n}} \frac{1-n}{\varepsilon^{n}}
$$

The coefficient $A(T)$ was chosen according to Paterson (1994), and $n=3$. There is a tuning parameter $m$ in $A(T)$ (Hooke, 1981) which was determined by comparing calculated and measured velocities at the glacier front. Its value is found to be $m=0.15$ for the Gregoriev ice cap.

The boundary conditions at the surface and the bottom of the glacier are: at the upper surface $\sigma_{i k} n_{k}=0$, where $n_{k}$ is the component normal to the surface at $z=h_{\mathrm{s}}(x)$, and the 

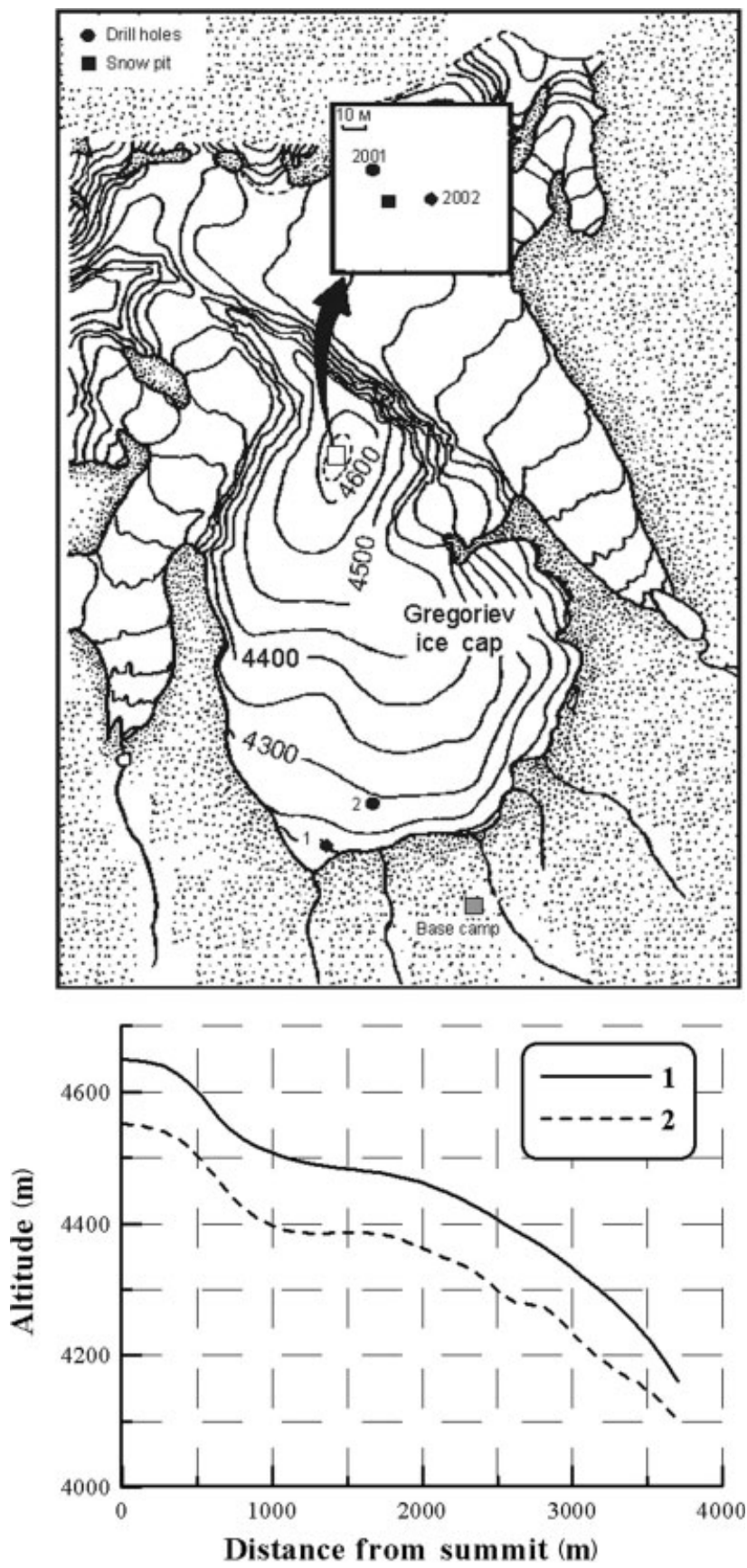

Fig. 1. Map (a) and longitudinal profiles (b) of the Gregoriev ice cap.

c velocity $\vec{v} \equiv\{u, w\}=0$ at $z=h_{\mathrm{b}}(x)$. They allow us to formulate the problem in terms of the stress deviators, and to find $\sigma_{z z}$ at the surface for Equation (2):

$$
\left.\sigma_{z z}\right|_{z=h_{\mathrm{s}}}=\frac{\mathrm{d} h_{\mathrm{s}}}{\mathrm{d} x} \alpha\left(2 \sigma_{x x}^{\prime}+\sigma_{y y}^{\prime}\right), \quad \alpha=\frac{\frac{\mathrm{d} h_{\mathrm{s}}}{\mathrm{d} x}}{\left[1-\left(\frac{\mathrm{d} h_{\mathrm{s}}}{\mathrm{d} x}\right)^{2}\right]} .
$$

At the summit, where $x=0$, we used the boundary conditions at the ice divide (Corcuera and others, 2001): horizontal velocity $u=0, \sigma_{x z}^{\prime}=0$. The boundary $x=L_{0}$ is located in the glacier. This boundary is close to the glacier front, and we used the following equation as the boundary condition at $x=L_{0}$ : the derivative of horizontal velocity $(\partial u / \partial x)\left(L_{0}, z\right)=0$.

After substitution of Equation (3) into Equation (2), and taking into account Equation (5), the following system of

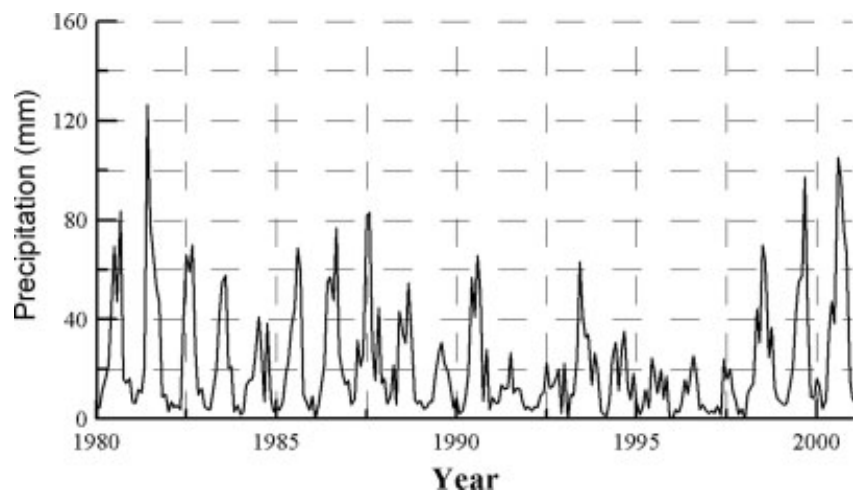

Fig. 2. Precipitation at the Tien Shan station.

integral-differential equations for the velocities in the glacier can be written instead of Equation (1):

$$
\begin{aligned}
& \frac{\partial u}{\partial x}+\frac{u}{b} \frac{\mathrm{d} b}{\mathrm{~d} x}+\frac{\partial w}{\partial z}=0 \\
& 4 \frac{\partial}{\partial x}\left(\eta \frac{\partial u}{\partial x}\right)+2 \frac{\partial}{\partial x}\left(\eta \frac{u}{b} \frac{\partial b}{\partial x}\right)+\frac{\partial^{2}}{\partial x^{2}} \int_{z}^{h_{\mathrm{s}}} \eta\left(\frac{\partial u}{\partial z}+\frac{\partial w}{\partial x}\right) \mathrm{d} z \\
& \quad+\frac{\partial}{\partial z}\left(\eta \frac{\partial u}{\partial z}\right)+\frac{\partial}{\partial z}\left(\eta \frac{\partial w}{\partial x}\right)+4 \frac{\mathrm{d}}{\mathrm{d} x}\left[\left.\alpha \frac{\mathrm{d} h_{s}}{\mathrm{~d} x}\left(\eta \frac{\partial u}{\partial x}\right)\right|_{z=h_{\mathrm{s}}}\right] \\
& \quad+2 \frac{\mathrm{d}}{\mathrm{d} x}\left[\left.\alpha \frac{\mathrm{d} h_{s}}{\mathrm{~d} x}\left(\eta \frac{u}{b} \frac{\mathrm{d} b}{\mathrm{~d} x}\right)\right|_{z=h_{\mathrm{s}}}\right]=\rho g \frac{\mathrm{d} h_{\mathrm{s}}}{\mathrm{d} x}
\end{aligned}
$$

The two last terms on the lefthand side come from the extra term in Equation (2) that does not appear in Pattyn's analysis. This system does not explicitly contain a time variable, and it is diagnostic (D.R. MacAyeal, unpublished information). Its solution describes a steady-state flow corresponding to the upper and bottom surfaces of the glacier. The prognostic equation which determines an evolution of the shape of the glacier is based on the mass-balance equation:

$$
\frac{1}{b} \frac{\partial(\bar{u} H b)}{\partial x}=a_{0}-\frac{\partial h_{s}}{\partial t}
$$

where $\bar{u}$ is the average horizontal velocity in the ice, $H$ is the thickness of the glacier and $a_{0}$ determines the mass balance at the surface.

The viscosity of ice depends on temperature which obeys the following equations:

$$
\begin{aligned}
\frac{\partial T}{\partial t}= & \chi\left(\frac{\partial^{2} T}{\partial x^{2}}+\frac{1}{b} \frac{\mathrm{d} b}{\mathrm{~d} x} \frac{\partial T}{\partial x}+\frac{\partial^{2} T}{\partial z^{2}}\right) \\
& -\left(u \frac{\partial T}{\partial x}+w \frac{\partial T}{\partial z}\right)+\frac{\sigma_{i k} \dot{\varepsilon}_{i k}}{\rho C} \\
& \quad 0<x<L_{0} ; \quad h_{\mathrm{b}}(x)<z<h_{\mathrm{s}}(x) ; \\
-k \frac{\partial T}{\partial z}\left(x, h_{\mathrm{s}}, t\right)= & \theta(t)\left[\mu(x, t)-T\left(x, h_{s}, t\right)\right]+q_{\mathrm{eff}}(t) \\
T\left(x, h_{\mathrm{b}}, t\right)= & T_{\mathrm{b}}(x) \\
T(0, z, t)= & T_{1}(z, t) \\
T\left(L_{0}, z, t\right)= & T_{2}(z, t) \\
T(x, z, 0)= & T_{0}(x, z)
\end{aligned}
$$

where $\chi$ is the thermal diffusivity $\left(1.12 \times 10^{-6} \mathrm{~m}^{2} \mathrm{~s}^{-1}\right), C$ is the heat capacity, $\mu(x, t)$ is air temperature, $\theta(t)$ is the effective energy-exchange coefficient (Paterson and Clarke, 1978), $q_{\text {eff }}(t)$ is the heat flux released due to meltwater refreezing, $T_{\mathrm{b}}$ is temperature at the glacier bottom and $T_{0}$ is 


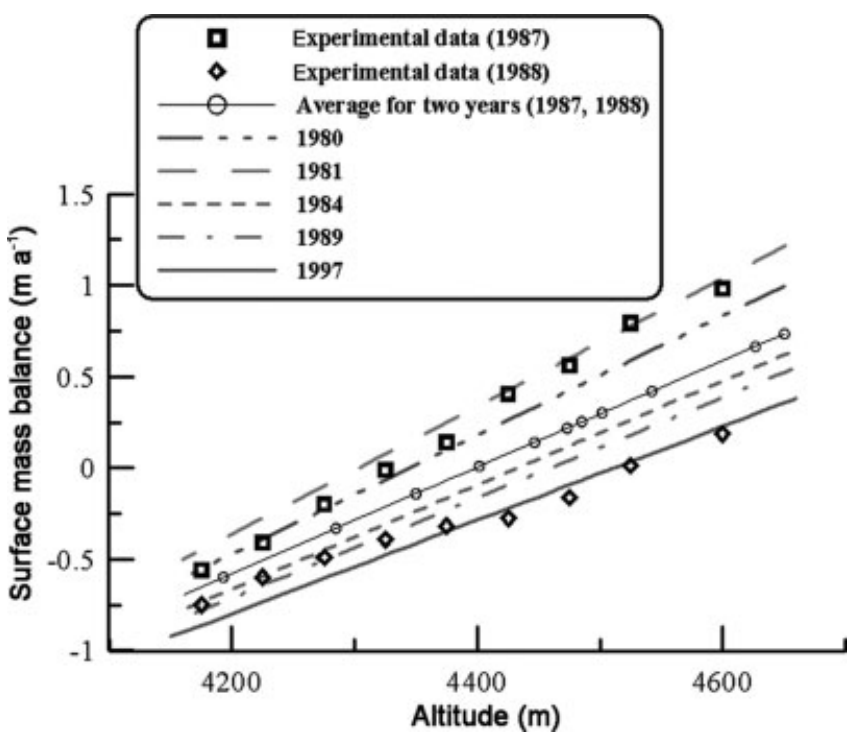

Fig. 3. Surface mass balance on the Gregoriev ice cap.

the initial temperature in the ice. (We use the conventional summation notation for tensors.)

At $x=0$ and $x=L_{0}$ the boundary temperatures $T_{1}(z, t)$ and $T_{2}(z, t)$ were taken from solution of the following auxiliary problems:

$$
\begin{aligned}
\frac{\partial T_{i}}{\partial t} & =\chi \frac{\partial^{2} T_{i}}{\partial z^{2}}, \quad h_{\mathrm{b}}<z<h_{\mathrm{s}} ; \quad i=1,2 ; \\
-k \frac{\partial T_{i}}{\partial z}\left(h_{\mathrm{s}}, t\right) & =\theta(t)\left[\mu(t)-T_{i}\left(h_{\mathrm{s}}, t\right)\right]+q_{\mathrm{eff}}(t), \\
T_{i}\left(h_{\mathrm{b}}, t\right) & =T_{\mathrm{b}} ; \\
T_{i}(z, 0) & =T_{0}(z) .
\end{aligned}
$$

\section{METHOD}

Calculation of velocities is based on the diagnostic system (Equation (6)) at each time-step using temperatures calculated using the set of Equations (8). The new location of the surface, $h_{s}$, is calculated from the mass-balance equation (7), and then temperatures are calculated at each new timestep.

The solution of the non-linear system of equations is determined by an iteration procedure in variables $\xi=\left(h_{\mathrm{s}}-z\right) / H$ and $x$ (Pattyn, 2000). It allows us to

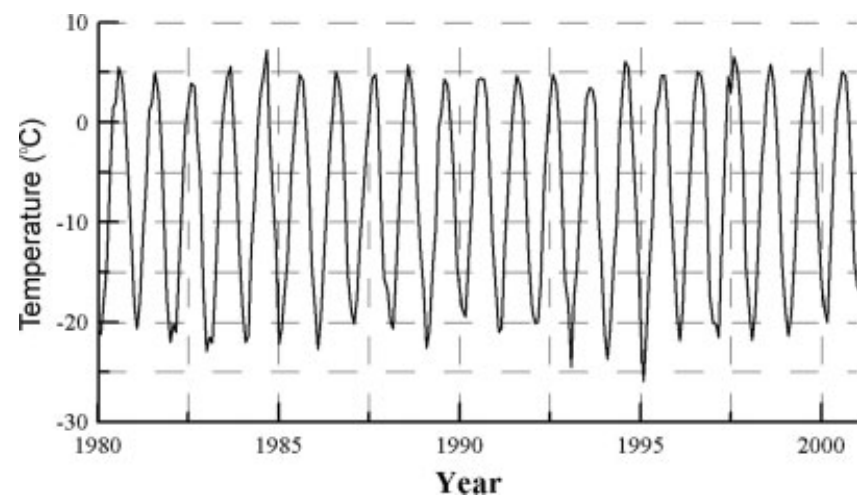

Fig. 4. Monthly average air temperature at the Tien Shan station.

transform the complex cross-section occupied by the glacier in a rectangular region $\Pi=\left\{0 \leq x \leq L_{0}, 0 \leq \xi \leq 1\right\}$. In these variables the diagnostic system is

$$
\begin{aligned}
\frac{\partial u}{\partial x} & +\xi_{x}^{\prime} \frac{\partial u}{\partial \xi}+\frac{u}{b} \frac{\mathrm{d} b}{\mathrm{~d} x}-\frac{1}{H} \frac{\partial w}{\partial \xi}=0 ; \\
4 & \frac{\partial}{\partial x}\left(\eta \frac{\partial u}{\partial x}\right)+4 \frac{\partial}{\partial x}\left(\eta \xi_{x}^{\prime} \frac{\partial u}{\partial \xi}\right)+4 \xi_{x}^{\prime} \frac{\partial}{\partial \xi}\left(\eta \frac{\partial u}{\partial x}\right) \\
& +4 \xi_{x}^{\prime} \frac{\partial}{\partial \xi}\left(\eta \xi_{x}^{\prime} \frac{\partial u}{\partial \xi}\right)+2 \frac{\partial}{\partial x}\left(\eta \frac{u}{b} \frac{\mathrm{d} b}{\mathrm{~d} x}\right)+2 \xi_{x}^{\prime} \frac{\partial}{\partial \xi}\left(\eta \frac{u}{b} \frac{\mathrm{d} b}{\mathrm{~d} x}\right) \\
& -2 \xi_{x}^{\prime} \frac{\partial}{\partial x}\left(\eta \frac{\partial u}{\partial \xi}\right)+2 \xi_{x}^{\prime} \frac{\partial}{\partial x}\left[H \eta\left(\frac{\partial w}{\partial x}+\xi_{x}^{\prime} \frac{\partial w}{\partial \xi}\right)\right] \\
& -\left(\xi_{x x}^{\prime \prime}-\frac{1}{H} H_{x}^{\prime} \xi_{x}^{\prime}\right) \eta \frac{\partial u}{\partial \xi} \\
& +\left(\xi_{x x}^{\prime \prime}-\frac{1}{H} H_{x}^{\prime} \xi_{x}^{\prime}\right) H \eta\left(\frac{\partial w}{\partial x}+\xi_{x}^{\prime} \frac{\partial w}{\partial \xi}\right) \\
& -\left(\xi_{x}^{\prime 2}-\frac{1}{H^{2}}\right) \frac{\partial}{\partial \xi}\left(\eta \frac{\partial u}{\partial \xi}\right) \\
& +\left(\xi_{x}^{\prime 2}-\frac{1}{H^{2}}\right) H \frac{\partial}{\partial \xi}\left[\eta\left(\frac{\partial w}{\partial x}+\xi_{x}^{\prime} \frac{\partial w}{\partial \xi}\right)\right] \\
& -\frac{\partial^{2}}{\partial x^{2}} \int_{0}^{\xi} \frac{\partial u}{\partial \tilde{\xi}} \mathrm{d} \tilde{\xi}+\frac{\partial^{2}}{\partial x^{2}} \int_{0}^{\xi} H \eta\left(\frac{\partial w}{\partial x}+\xi_{x}^{\prime} \frac{\partial w}{\partial \tilde{\xi}}\right) \mathrm{d} \tilde{\xi} \\
& +4 \frac{\mathrm{d}}{\mathrm{d} x}\left[\alpha \frac{\mathrm{d} h_{s}}{\mathrm{~d} x}\left(\eta \frac{\partial u}{\partial x}\right)_{\xi=0}\right]+4 \frac{\mathrm{d}}{\mathrm{d} x}\left[\alpha \frac{\mathrm{d} h_{s}}{\mathrm{~d} x}\left(\eta \xi_{x}^{\prime} \frac{\partial u}{\partial x}\right)_{\xi=0}\right] \\
+ & \frac{\mathrm{d}}{\mathrm{d} x}\left[\alpha \frac{\mathrm{d} h_{s}}{\mathrm{~d} x} \frac{1}{b} \frac{\mathrm{d} b}{\mathrm{~d} x}(\eta u)_{\xi=0}\right]=\rho g \frac{\mathrm{d} h_{s}}{\mathrm{~d} x} .
\end{aligned}
$$

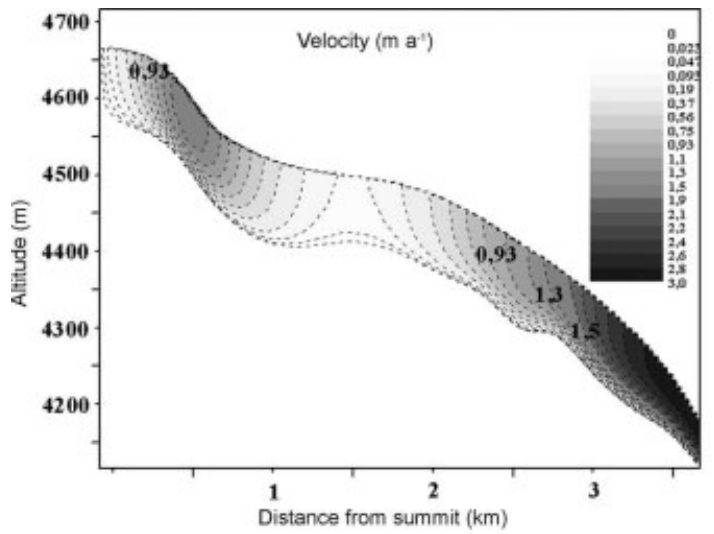

Fig. 5. Horizontal velocity in the Gregoriev ice cap: (a) in 1980; and (b) forecast for 2050. 


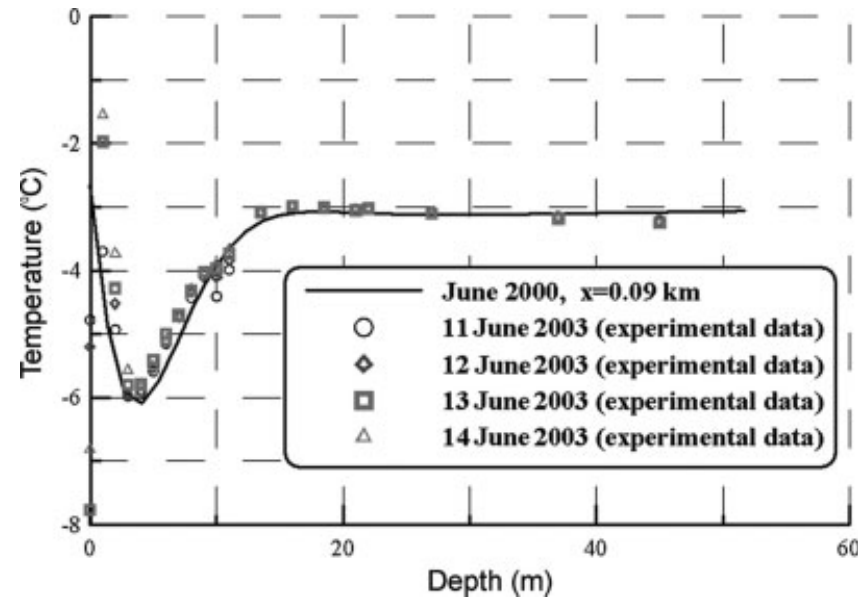

Fig. 6. Observed and calculated temperature profiles in the Gregoriev ice cap.

We have developed the finite-difference code GregFlow of these equations with first-order approximation in boundary nodes, and the second-order approximation in the internal nodes (Fletcher, 1991). A similar approach is used for the heat problem (Equation (8)).

\section{APPROXIMATION OF THE BOUNDARY CONDITION AT THE SURFACE}

The boundary condition at the free surface was combined with Equation (2) to be consistent in the neighboring nodes. Computer tests show that it allows the number of iterations and the number of nodes in the vertical direction to achieve the needed accuracy to be reduced.

\section{THE INPUT DATA}

The term $a_{0}$ in Equation (7) is the difference between precipitation $a_{1}$ and ablation rate $a_{2}$, that is, the amount of meltwater runoff in summer months. Precipitation and ablation were approximated by linear functions of

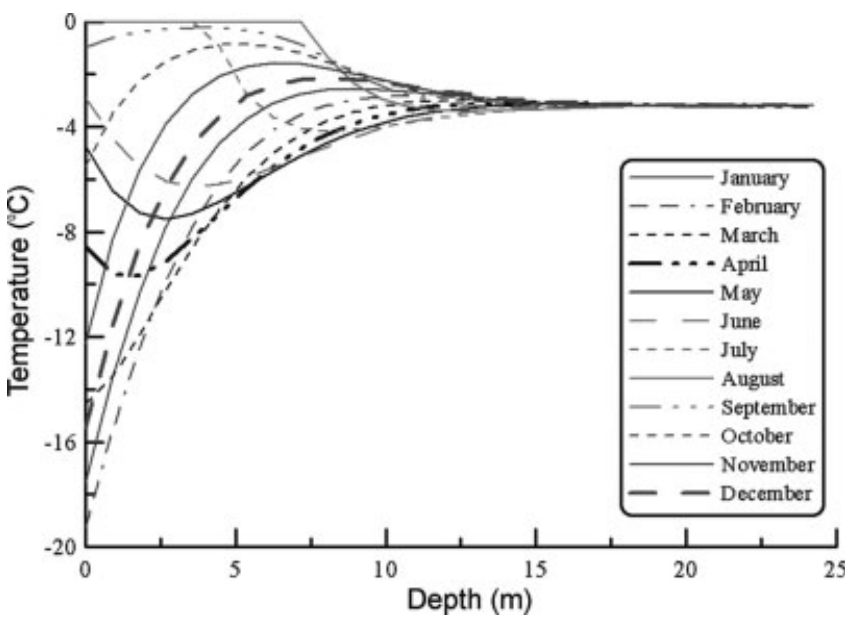

Fig. 7. Calculated temperature profiles at $x \approx 0.18 \mathrm{~km}$ from the summit.

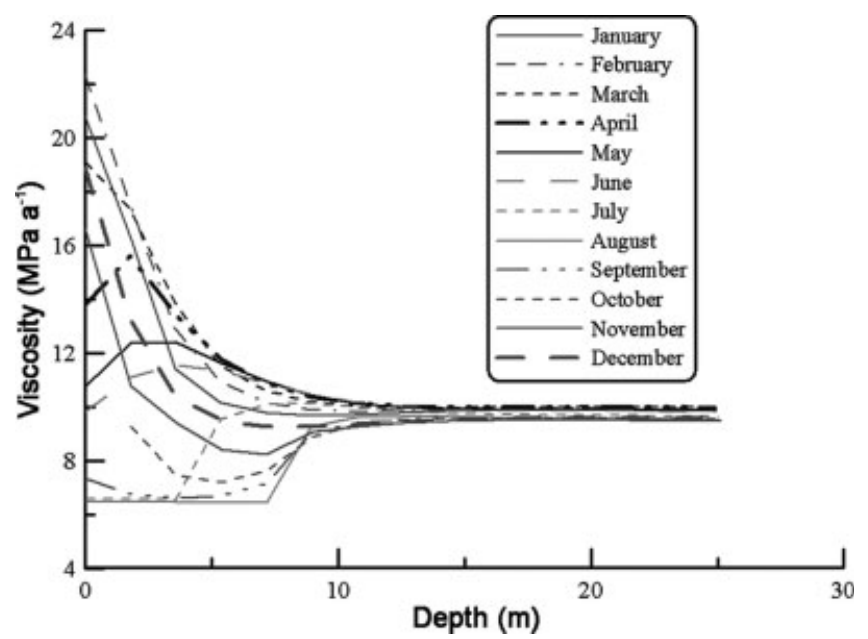

Fig. 8. Viscosity profiles at $x \approx 0.18 \mathrm{~km}$ from the summit.

elevation, $h_{\mathrm{s}}(x)$ :

$$
\begin{array}{r}
a_{1}(x, t)=\left[1+(1.5 / 500)\left(h_{s}(x)-4100\right)\right] a(t), \\
a_{2}(x, t)=\left[1.15-(1.15 / 550)\left(h_{s}(x)-4100\right)\right] \\
\cdot \exp \left[-(t-n-0.64)^{2} / 0.005\right] / I,
\end{array}
$$

where $n$ is a current year, $t$ is time in years, $I=$ $\int_{0}^{1} \exp \left[-(t-0.64)^{2} / 0.005\right] \mathrm{d} t$, and $a(t)$ is precipitation at $4100 \mathrm{~m}$ elevation, equal to that at the Tien Shan meteorological station (Fig. 2).

The coefficients in Equations (9) are determined by comparison of the balance $a_{0}=a_{1}-a_{2}$ to the average value measured in 1987 and 1988 (Mikhalenko, 1989; Djurgerov and others, 1995) (Fig. 3).

Air temperatures $\mu(x, t)$ are based on data at the Tien Shan meteorological station (Arkhipov and others, 2004) (Fig. 4). The change of temperature with elevation for this region is $0.233^{\circ} \mathrm{C}$ by $100 \mathrm{~m}$ (Makarevich and others, 1969):

$$
\mu(x, t)=T(t)-0.00233\left(h_{s}(x)-h_{0}\right),
$$

where $h_{0}$ is the elevation of the Tien Shan meteorological station (3615 ma.s.l.).

\section{RESULTS}

\subsection{Evolution of the Gregoriev ice cap}

The calculations show that the velocity in ice varies from 0 to $3 \mathrm{~m} \mathrm{a}^{-1}$ along the glacier flowline. The maximum velocity is shifted from the lowest part towards the middle part of the Gregoriev ice cap for the studied period 1980-2050. The flow velocity near the front of the glacier is decreased for two reasons. The first is negative mass balance that results in thinning of the glacier tongue. The second is connected with deeper penetration of cold temperatures from the surface to the bed because of thinning of the glacier in its lower part. As a result, the internal heating becomes smaller in this part of the glacier and moderates the flow.

The changes of shape of the surface are mainly determined by the mass balance at the surface. At the surface at elevations $h>4400 \mathrm{~m}$ the mass balance is positive, which corresponds to observations (Mikhalenko, 1989). At $h<4400 \mathrm{~m}$, negative mass balance at the surface occurs. Near the glacier front, there is strong thinning and decrease 

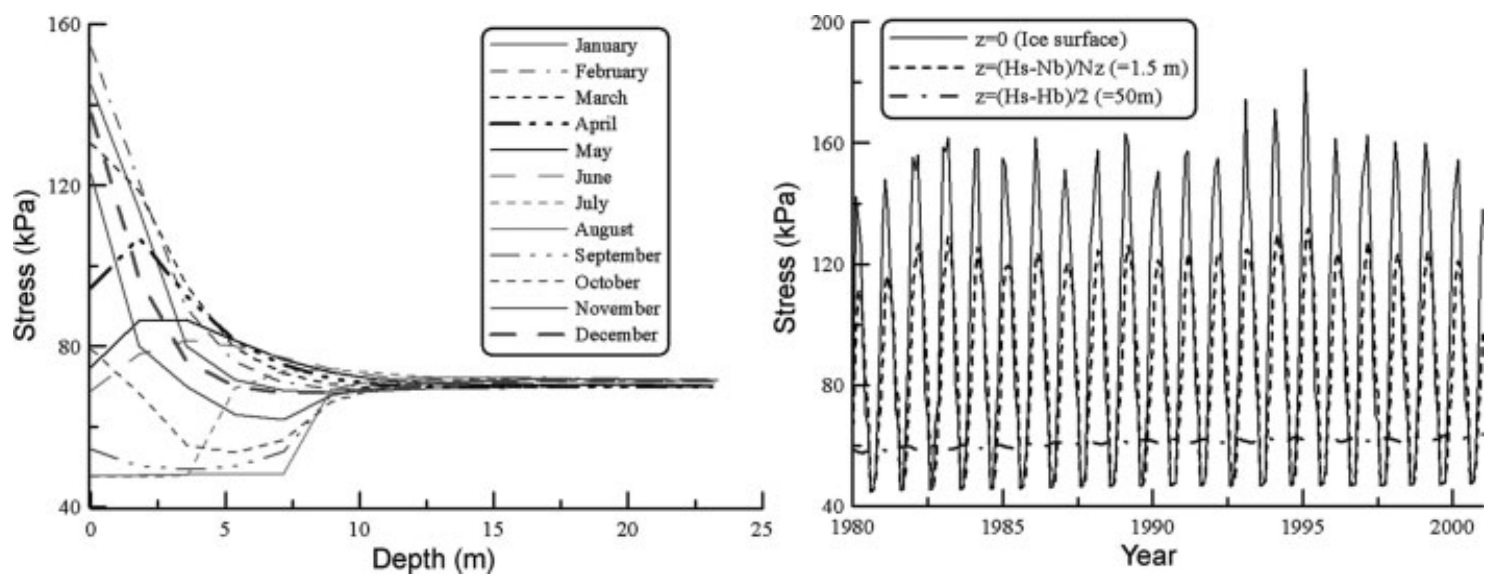

Fig. 9. Longitudinal stress deviator profiles $\left(\sigma_{x x}^{\prime}\right)($ a) and the longitudinal stress deviator at different depths $(\mathrm{b})$ at $x \approx 0.18 \mathrm{~km}$ from the summit.

in glacier length at a rate of $\approx 0.5 \mathrm{~m} \mathrm{a}^{-1}$, which increases with time. Figure 5 compares the cross-section of the Gregoriev ice cap in 1980 (Fig. 5a) with that forecast for 2050 (Fig. 5b) assuming that air-temperature and precipitation trends will remain the same in the future as they were in 1930-2000.

\subsection{Seasonal changes of temperature, stresses and velocities in subsurface layer of Gregoriev glacier}

The borehole temperatures at $h_{s} \approx 4600 \mathrm{~m}$ were measured in the borehole in 2003 and calculated for the same time (Fig. 6). The calculations were done with a time-step of 1 month. The calculated temperatures for each month in 2003 are shown in Figure 7.

The heat source $q_{\text {eff }}(t)$ results in intense heating of the subsurface of the glacier in July and August (Fig. 7). The zero temperature front propagates down to $8 \mathrm{~m}$ depth. Seasonal changes of temperature induce variation of the viscosity in the subsurface layers (Fig. 8). A decrease of ice temperature from $0^{\circ} \mathrm{C}$ to $-20^{\circ} \mathrm{C}$ causes variation of the coefficient $A(T)$ in a range from $6.8 \times 10^{-15}$ to $1.7 \times 10^{-16} \mathrm{~s}^{-1} \mathrm{kPa}^{-3}$. The viscosity $\eta$ increases 3.5 times. Outside the layer of seasonal temperature changes $(z \geq 15 \mathrm{~m})$, there is practically no change in viscosity (Fig. 8).

Seasonal oscillations of the stress deviator follow the changes of viscosity (Fig. 9a). In winter months, changes of

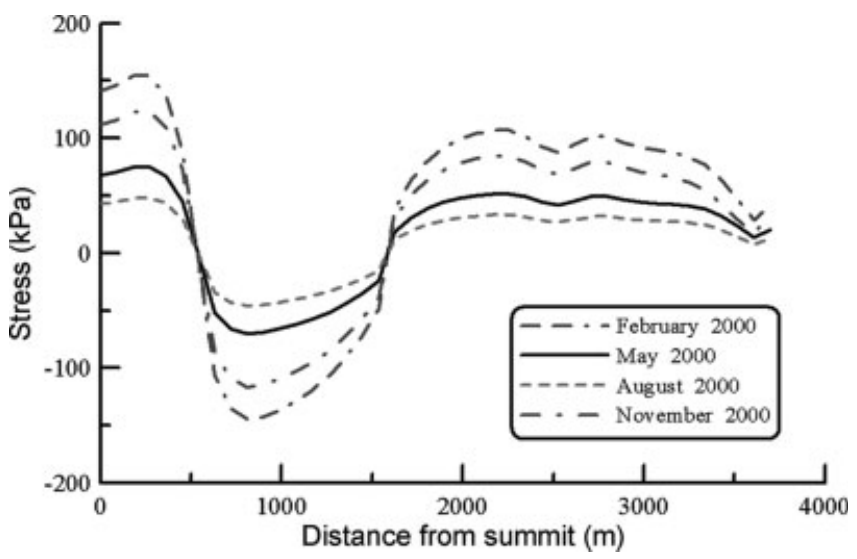

Fig. 10. Longitudinal stress deviator $\sigma_{x x}^{\prime}$ at the surface. the stress deviator $\sigma_{x x}^{\prime}$ can exceed the strength of ice $\left(\approx 10^{2} \mathrm{kPa}\right)$, which can result in crack formation in the subsurface layers (Figs $9 \mathrm{~b}$ and 10).

The flow velocity changes in accordance with changes in the glacier slope. At $0<x<2.2 \mathrm{~km}$, the slope increases with time, and the velocity increases also. At $x>2.5 \mathrm{~km}$, the slope, ice velocity and ice thickness decrease (Fig. 11).

The influence of the term $(\mathrm{d} / \mathrm{d} x)\left(\left.\sigma_{z z}\right|_{z=h_{\mathrm{s}}}\right)$ in Equation (2) on the solution increases with the slope of the glacier. For the Gregoriev ice cap, accounting for this term results in 5\% difference of the numerical solution that is compared with input of the other integral term in Equation (2).

\section{CONCLUSION}

The thermodynamic state of the Gregoriev ice cap was studied by mathematical modeling. The observed data on the mass balance of the glacier, its surface shape and meteorological data (precipitation and air temperatures) were used as input to the model. For the time interval considered in this study, 1980-2050, the maximum velocity shifts from the lowest part toward the middle part of the Gregoriev ice cap. The ice velocity varies from 0 to $3 \mathrm{~m} \mathrm{a}^{-1}$

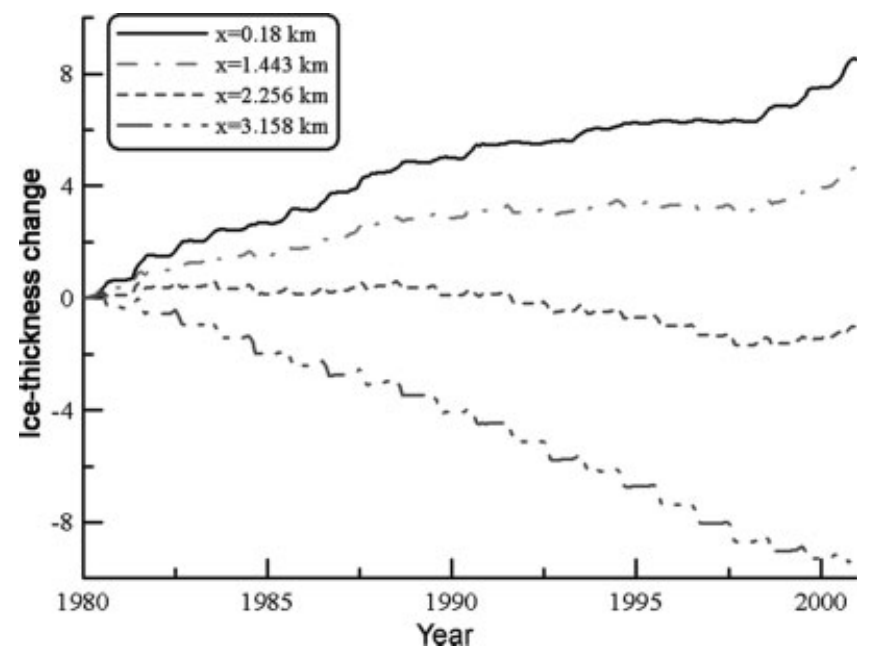

Fig. 11. Ice-thickness changes at some distances from the summit. 
along the glacier flowline, and the flow velocity near the front of the glacier is decreased. Seasonal variations of temperature result in changes of viscosity of ice, and, as a consequence, significant additional longitudinal deviatoric stress arises in places where the surface slope has large gradients. The resulting stresses can exceed the strength of the ice and result in crack formation. The derived changes of the glacier shape show the degradation and decrease of glacier extent on the south slope of Terskey Ala Tau.

\section{ACKNOWLEDGEMENT}

This work was supported by the International Science and Technology Center (grant 2947).

\section{REFERENCES}

Arkhipov, S.M., V.N. Mikhalenko, M.G. Kunakhovich, A.N. Dikikh and O.V. Nagornov. 2004. Termicheskii rezhim, usloviia I'doobrazovaniia i akkumulyatsiia na ladnike Grigor'eva (Tyan'-Shan') v 1962-2001 gg. [Thermal regime, ice types and accumulation in Grigor'ev Glacier, Tien Shan, 1962-2001]. Mater. Glyatsiol. Issled. 96, 77-83.

Corcuera, M.I., F.J. Navarro, C. Martín, J. Calvet and L. Ximenis. 2001. Finite element modelling of the steady-state dynamics of Johnsons Glacier. Mater. Glyatsiol. Issled. 90, 156-168.
Djurgerov, M.B. and 17 others. 1995. Oledenenye Tien-Shanya [Glaciation of Tien Shan]. Moscow, Russian Academy of Sciences.

Fletcher, C.A.J. 1991. Computational techniques for fluid dynamics. New York, etc., Springer-Verlag.

Hooke, R.LeB. 1981. Flow law for polycrystalline ice in glaciers: comparison of theoretical predictions, laboratory data, and field measurements. Rev. Geophys. Space Phys., 19(4), 664-672.

Hutter, K. 1983. Theoretical glaciology; material science of ice and the mechanics of glaciers and ice sheets. Dordrecht, etc., D. Reidel Publishing Co./Tokyo, Terra Scientific Publishing Co.

Huybrechts, P. and J. Oerlemans. 1988. Evolution of the East Antarctic ice sheet: a numerical study of thermo-mechanical response patterns with changing climate. Ann. Glaciol., 11, 52-59.

Makarevich, K.G. and 7 others. 1969. Oledenenye Zailiyskogo Alatau [Glacierization of the Zailiyskiy Ala-Tau]. Moscow, Nauka.

Mikhalenko, V.N. 1989. Osobennosti massoobmena lednikov ploskikh vershin vnutrennego Tyan'-Shanya [Peculiarities of the mass exchange of flat summit glaciers of interior Tyan'Shan']. Mater. Glyatsiol. Issled. 65, 86-92.

Paterson, W.S.B. 1994. The physics of glaciers. Third edition. Oxford, etc., Elsevier.

Paterson, W.S.B. and G.K.C. Clarke. 1978. Comparison of theoretical and observed temperature profiles in Devon Island ice cap, Canada. Geophys. J. R. Astronom. Soc., 55(3), 615-632.

Pattyn, F. 2000. Ice-sheet modelling at different spatial resolutions: focus on the grounding zone. Ann. Glaciol., 31, 211-216. 